\title{
Computers and pedagogy: Replacing telling with interactive computer-programmed instruction
}

\author{
DARREL E. BOSTOW, KALE M. KRITCH, and BRENDAN F. TOMPKINS \\ University of South Florida, Tampa, Florida
}

\begin{abstract}
Programmed instruction has been overlooked as a way of implementing more intensive application of learning principles, possibly because it has not been well understood. Today, most of the hardware problems of past teaching machines have been solved. Instructors can now expand their effectiveness and productivity by shifting to the creation of both classroom tests and computer-interactive tutorials, a change that would leave more time for personal interaction with students. But a better understanding of the contingency of reinforcement and the science in which this concept has evolved is necessary. The computer as a teaching machine has yet to be fully exploited.
\end{abstract}

Pedagogy refers to the work or functions of the teacherto instructional techniques that have evolved as an art and also from a science of learning. Pedagogical technology often refers to material things, such as overhead projectors, typewriters, and computers, but it can also refer to instructional techniques.

Pedagogy is not always effective. The stereotypical technique of college teaching is, of course, the lecture. Unfortunately, lecturing is usually defined by its form without reference to changes in the listener. Indeed, the listener usually remains passive. Effective teaching is, perhaps, better defined as changing the behavior of the student in durable ways. Teaching is then tied to its effects. From this point of view, there is no teaching when there is no learning.

The inadequacy of exclusively "telling" is often recognized. Instructors add visual and audio technology to gain interest. Experimental research points to the added advantage of learner participation in college instruction (Keller, 1965; C. C. Kulik, J. A. Kulik, \& Cohen, 1980; J. A. Kulik, Jaksa, \& C. C. Kulik, 1978; J. A. Kulik, C. C. Kulik, \& Bangert-Drowns, 1988; J. A. Kulik, C. C. Kulik, $\&$ Charmichael, 1974). The lecture/discussion is a blend of lecturing and participation, but it is rarely interactive for most of the students.

The learner more significantly "interacts" when he/she is required to overtly respond to the instructional material. Simply more interaction is not enough. Meaningful interaction connects with successful behavior. A science of learning has revealed that consequences for successful performance should be made precisely contingent on what has been done. Behavior strengthened through successful interaction provides increased motivation for both the student and the teacher.

Why do passive techniques of instruction continue to be used? Teachers (including professors) talk rather than

Correspondence should be addressed to D. E. Bostow, College of Education, Department of Psychological and Social Foundations, University of South Florida, Tampa, FL 33620 (e-mail: bostow@tempest. coedu.usf.edu). arrange more effective contingencies because that is how they have been taught in the past and that is what most of their colleagues are currently doing. The "chalk and talk" method is so respected and widespread that one who lectures is unlikely to be criticized. Variant techniques often fail to win the support of colleagues or administrators.

Interactive pedagogy also suffers from the intrusion of other responsibilities, such as grant seeking, committee participation, and paper work. Add to this the fact that many students want lectures. They have grown up in a culture of movies and television. They have been passive in school most of the time. They have allowed their teachers to do the work. But they now want an "exciting" or "stimulating" speaker-not unlike the last television show that they have seen. But possibly the deepest problem of all is the lack of awareness that better technologies are available. Education has yet to embrace powerful technologies of instruction.

How could teaching be improved? We might begin by looking at what a good private tutor does and relate it to what a machine might do. The tutor repeatedly sets the occasions for responding, prompts responses to be acquired, evaluates them, and either corrects them or signals successful advancement. A good instructor in music, theater, or swimming maintains a continual rate of interaction. Although actuarial studies have rarely been done, casual observation suggests that the rate of interaction with a private teacher is often on the order of twice per minute. At such a rate, a typical classroom teacher with 30 students would provide differential feedback perhaps 3,000 times in a 50-min class period. It is clear that without better pedagogical techniques, this task is simply impossible. Without the infusion of technology to close this gap, our educational system will continue to lose ground. Better techniques of instruction are available, and there is considerable evidence in support of their effectiveness (Lloyd \& Lloyd, 1992; Vargas \& Vargas, 1992).

\section{The Central Issue}

It has been shown that the effectiveness of instruction correlates highly with the presence of reinforcement con- 
tingencies, or learning units. A learning unit or contingency contains three critical parts. It is composed of (1) the momentary setting in which a student responds, (2) the behavior that the student is to emit, and (3) the consequences that immediately follow the performance. We measure the learning unit by noting the behavior emitted and the immediately contingent consequence. The student must do something, and a contingently dependent consequence must immediately follow.

But how can frequent and precisely delivered reinforcement contingencies be accomplished when a teacher or professor is assigned a room full of students? The solution is technological. Techniques described in the research literature (see Lloyd \& Lloyd, 1992) following Keller's (1968) description of his "personalized system of instruction" (PSI) have revealed helpful methods for increasing the density of meaningful learning contingencies. Now, with the help of microcomputers as teaching machines, the density of "learning units" can be further increased to rates of once every $30 \mathrm{sec}$ for each student.

Recognizing or building computer instructional programs that are truly programmed, however, requires a thorough knowledge of operant learning principles. Unfortunately, this field of behavior analysis is often poorly represented in our media. Programmed instruction requires the highly disciplined application of the techniques called shaping, fading, priming, and prompting. It requires the elemental breakdown of learning objectives into minimal units which compose programs of changing contingencies (see Kritch \& Bostow, 1994). The pedagogical techniques that create learning units or contingencies at a rapid rate also require appropriate software programs (see Allen Elliot's, 1994, PC-CAI, for a low-cost and particularly useful example).

Computers are modern-day teaching machines. But here we are not talking about fancy simulations, or the booms, beeps, and buzzes of popular commercial software. Computers can perform a far more important function. They can precisely deliver learning units in a consistent and ordered sequence-called a program. They can evaluate students' overt responses. They can accomplish the kind of differential reinforcement that is otherwise accomplished only by a private instructor. Unfortunately, hardware capabilities have outstripped the quality of available programs. Software manufacturers have produced programs that usually ignore good instructional theory (Vargas \& Vargas, 1992) in favor of emotional and commercial appeal.

Computers can make dramatic improvements when they are used simply to evaluate student performance more frequently. They can be used primarily as testing devices. Research has revealed that students more readily perform the objectives of instruction when they know what is required (Hannafin \& Peck, 1988; Hanum \& Briggs, 1982; J. A. Kulik et al., 1978; Laham \& Caldwell, 1979; Peters, 1975; Semb, Hopkins, \& Hursh, 1973). In this case, the instructor can first compose the test items that will be used to determine grades. (Paper text manufacturers typically provide tests as computer word- processing files.) The instructor can review these test items and convert them into questions - study questions, that is, which tell the student how to prepare for the exam item. These study questions can be handed out as part of the syllabus, in preparation for computer quizzes.

Computers now make test administration and scoring easier. They can be used to administer "filtering" examinations. Thus, the instructor can more easily give an examination first, analyze the results immediately, and then have question/answer sessions. When remediation is required, students who fail portions of the quizzes have the opportunity to retake and improve their scores. All of this usually produces students who are better prepared for question and answer sessions, more lively and informed discussions, and better performance on final examinations (J. A. Kulik, et al., 1978; Semb et al., 1973).

Computers can improve information security. Diskettes can be uncopyable and available in the computer lab only. Alternative forms of examinations can be constructed so that students cannot copy from each other. Authoring programs are now available (see, e.g., Elliott's, 1994, PC-CAI) which can randomly draw from a pool of items, making it impossible for students to couple up with neighbors while working through examinations. Differently colored screen backgrounds can be used to make sure students beside each other are working on different quizzes. Every student can immediately know his/her current average in the course and the score's relative standing, because the instructor or lab assistant responds to a spreadsheet.

Direct observation of preparation has revealed that students do most of their preparation immediately before examinations (Mawhinney, Bostow, Laws, Blumenfeld, \& Hopkins, 1971). The use of weekly filtering and remedial quizzes almost guarantees better student preparation. Lecture/discussions can then play a different role. They can become optional (their instructional utility is still sometimes questioned; see, e.g., Calhoun, 1976; Roberts, Suderman, Suderman, \& Semb, 1990). Making lecture attendance optional has at least one advantage: it often results in attendance by a subset of students, those whose commitment to the course content goes beyond that induced by examination performance. Classroom discussion with this population of students is often a rich source of new ideas. 1

\section{Computers as Teachers}

Computers and software programs are helpful tools. As we have seen, they make the chores of testing, evaluating, outline and word processing, and record keeping easier. But perhaps the crowning achievement of computers is actual instruction itself. Someone must design the instruction, however. Someone must organize the interchanges between student and machine into a sequential series of small steps, each small step being a component leading to the desired terminal performance. We are back to the issue of instructional programming. This role of the teacher will never be replaced, and here we recommend that it be greatly expanded. 
As we have seen, truly "programmed" instruction is the sequential arrangement of learning units, otherwise called contingencies of reinforcement. Computerprogrammed instruction is similar to the programmed instruction of the past (Holland, Solomon, Doran, \& Frezza, 1976; Skinner, 1968). Many of the lessons learned years ago are now more relevant then ever. Creating computerprogrammed instruction is not easy, and we must train the designers in the commercial world better. Instructional programming requires a thorough knowledge of operant conditioning principles, principles often not given enough attention in pedagogy. Programmed instruction also requires the conviction that many of the products of instruction can be specified in advance-a conviction sometimes questioned by those who argue that objectives are to be constructed by learners themselves.

The formulation of objectives, design of instruction, and implementation of learning principles is a complex process. We should expect that the skill of creating computerprogrammed instruction should be taught at the computer, and it can be. For example, the first and second authors of this paper have assembled a computer-interactive tutorial about the creation of computer-programmed instructional tutorials (see Kritch \& Bostow, 1994). Using this tutorial, the teacher/programmer works through a series of instructional lessons and exercises that teach the principles and techniques of computer-programmed instruction. This package also contains the software necessary for students to begin creating their own instructional programs. Although the current package is delivered by MS-DOS machines, the instructional design principles are generic. (A useful accessory tutorial creation program for the Macintosh HyperCard authoring system has also been created by Kritch.)

\section{Summary}

The role of the teacher or professor can change significantly, thanks to both newly available hardware and techniques that have been available long but have been used little. Computers can often take over some of the instruction that was once relegated to lectures. The teacher need no longer simply "tell" and then occasionally test. Instead, the instructor can construct interactive exams that respond specifically, immediately, and sensitively to the student's developing performance. Much of the task of teaching in small steps can be taken over by available technologies.

Thus, the instructor's role can change from being primarily an expositor. The instructor is then available for individual consultation. Surprisingly, machines with programs that teach can bring the instructional staff more sensitively into contact with students. The automation of instruction can free the teacher from the most repetitious and laborious aspects of teaching, leaving time for relaxed and informal personal discussions. The teacher can become a mentor.

But technology can help only if it is applied. We must remember that technology comprises more than machines; it also includes techniques (Cooper, Heron, \&
Heward, 1987; Kritch \& Bostow, 1994; Sulzer-Azaroff $\&$ Mayer, 1991). Teachers at all levels must arrange more precise and frequent instructional contingencies if they are to produce the changes needed to sustain good teaching and learning. To do so, instructors need a better understanding of a science of behavior-the science that originally produced the pedagogical technology called programmed instruction. Only then will education begin to embrace the nearly unlimited power of the computer as a teacher.

\section{REFERENCES}

Calhoun, J. F. (1976). The combination of elements in the personalized system of instruction. Teaching of Psychology, 18, 205-211.

CoOper, J. O., Heron, T. E., \& Heward, W. L. (1987). Applied behavior analysis. Columbus, $\mathrm{OH}$ : Merrill.

Elliot, A. (1994). PC-CAI [Computer authoring program]. TexaSoft Inc., Box 1169, Cedar Hill, TX 75104.

Hannafin, M. J., \& Peck, K. L. (1988). The design, development, and evaluation of instructional software. New York: Macmillian.

HANUM, W., \& BRIGGS, L. (1982). How does instructional systems design differ from traditional instruction? Educational Technology, 22, 9-14.

Holland, J. G., Solomon, C., Doran, J., \& Frezza, D. A. (1976). The analysis of behavior in planning instruction. Reading, MA: AddisonWesley.

KELLER, F. S. (1965). New reinforcement contingencies in the classroom? American Psychologist, $20,542$.

KeLlER, F. S. (1968). "Goodbye, teacher ..." Journal of Applied Behavior Analysis, 1, 79-89.

KrITCH, K. M., \& Bostow, D. E. (1994). Creating computer programmed instruction [Computer program]. Tampa, FL: Customs Systems International, Inc.

Kulik, C. C., Kulik, J. A., \& CoHEN, P. A. (1980). Instructional technology and college teaching. Teaching of Psychology, 6, 213-216.

KULIK, J. A., JAKSA, P., \& KULIK, C. C. (1978). Research on component features of Keller's personalized system of instruction. Journal of Personalized Instruction, 3, 2-14.

Kulik, J. A., KuliK, C. C., \& Bangert-Drowns, R. L. (1988). Effectiveness of mastery learning programs: A meta-analysis. Ann Arbor, MI: University of Michigan, Center for Research on Learning and Teaching.

Kulik, J. A., Kulik, C. C., \& Charmichael, K. (1974). The Kellerplan in science teaching. Science, 188, 379-383.

LaHaM, S. L., \& Caldwell, E. C. (1979). Praecox discussion differentially affects student performance. Teaching of Psychology, 6, 213-216.

LARSON, N. (1994). Maxthink [Computer software program]. MaxThink, Inc., 2425B Channing Way, Berkeley, CA 94704.

LLOYD, K. E., \& LLOYD, M. E. (1992). Behavior analysis and technology in higher education. In R. P. West \& L. A. Hamerlynck (Eds.), Designs for excellence in education: The legacy of $B$. F Skinner (pp. 147-160). Longmont, CO: Sopris West.

MaWhinney, V. T., Bostow, D. E., Laws, D. R., Blumenfeld, G. J., \& HopkINS, B. L. (1971). A comparison of students' studying behavior produced by daily, weekly, and three-week testing schedules. Journal of Applied Behavior Analysis, 4, 247-264.

PETERS, R.D. (1975). Pre-quiz monitoring of study materials improves performance in two PSI courses. In J. M. Johnston (Ed.), Research and technology in college and university teaching (pp. 185-201). Gainesville, FL: Society for Behavioral Technology \& Engineering.

Roberts, M. S., Suderman, L., Suderman, R., \& Semb, G. (1990). Reading ability as a predictor in a behaviorally based psychology course. Teaching of Psychology, 17, 173-175.

Semb, G., Hopkins, B. L., \& Hursh, D. E. (1973). The effects of study questions and grades on student test performance in a college course. Journal of Personalized Instruction, 4, 129-135.

SKINNER, B. F. (1968). The technology of teaching. New York: Meredith. 
Sulzer-AzARoff, B., \& MAYER, G. R. (1991). Behavior analysis for lasting change. New York: Holt, Rinehart \& Winston.

Vargas, E. A., \& VArgas, J. S. (1992). Programmed instruction and teaching machines. In R. P. West \& L. A. Hamerlynck (Eds.), Designs for excellence in education: The legacy of B. F. Skinner (pp. 3369). Longmont, CO: Sopris West.

\section{NOTE}

1. The computer can also be a powerful tool for producing better writing skills. At the University of South Florida, students learn to compose better essays at the computer. They first collect thoughts in notebooks and transfer them into a computer outline processing program called MaxThink (see Neil Larson's, 1994, MaxThink). The instructor assigns readings and other tutorials while suggesting themes for student essays. The students submit copies of their developing outlines for instructor analysis-all of them on computer diskette files. These electronic drafts remain in the outline processor format, enabling the instructor to recommend changes in thought development, to insist that students implement suggested changes, and to employ software programs that evaluate grammar and syntax.

(Manuscript received December 2, 1994; revision accepted for publication February 21, 1995.) 